\title{
Study of complex systems II-utilization of a logic tree for studying physical properties of an emulsion food
}

\author{
Jiro KANAMORI ${ }^{1}$ \\ Fuji Oil Holdings Inc. R\&D Division for Future Creation \\ kanamori.jiro@gmail.com
}

\begin{abstract}
The addition of a strong gelling agent does not always produce a hard sausage. Mysterious phenomena are frequently observed in complex systems like food, and a novel method is needed for analyzing such complex systems. In this study, the factors relating to the hardness of sausage fortified with soy protein isolate (SPI) were investigated. Although the gelling ability of SPI with gums was lower than that of the control SPI, the hardness of the sausages fortified using SPI with gums was higher than that of the sausages fortified using the control SPI. The SPI with gums did not have higher emulsifying property than the control SPI, but the emulsions of the former were finer than that of the control. The experiment in a simple model system performed using a cutting mixer revealed that higher viscosity positively affected the emulsifying property. The effect of addition of gums on the hardness of the sausages was considered to be indirectly derived from their high viscosity. A logic tree explained the complex relation between the factors in sausage processing, and it will be a useful tool for analyzing complex systems.
\end{abstract}

\section{INTRODUCTION}

Food processing is a complex system associated with numerous factors. It is important to understand and control complex systems, which was done by a food expert traditionally. In my previous study, the utility of a meso-factor was discussed, and there will be many kinds of meso-factors discussed other than the filler effect, for example, rheological factors were often used in food processing.

Sausage - a traditional processed food-is one of such complex systems, which is affected by many factors: recipes, quality of raw materials, and processing conditions. Some kinds of ingredients-proteins, starches, and gums-have been used in the meat processing industry to improve the cost, quality of products, and controllability of processing

\footnotetext{
1 Current Affiliation: Macro Science Laboratory \#401 SpringTech Tsukuba Building, 2-1-15 Umezono, Tkuba-shi, Ibaraki-ken, JAPAN
} 
(Abdolghafour and Saghir, 2014; Lin and Mei, 2000; Andrès et al., 2006; Joly and Anderstein, 2009). Soy protein isolate (SPI) is a typical ingredient having physical properties like gelation and emulsification. It is being used as an extender and improver for a long time; it is also been expected to be used as a future foodstuff (Hoogenkamp, 2005; Liu, 2000; Lusas and Rhee, 1995).

The author and his co-workers found that the addition of gums was effective in SPI fortified sausages (Tsuge et al., 2004). However, we did not determine the factor because the sausage was too complex to analyze. In the present study, the factors relating to the hardness of sausage, in terms of addition of gums, were determined. The gelation property of SPI did not affect the hardness of sausage, and the emulsifying property of SPI did not affect the emulsion of sausage. The author resolved the incomprehensible results of the sausage using a logic tree, and the analyzing method for complex systems was discussed.

\section{MATERIALS AND METHODS}

\section{Materials}

Sodium (Na)-Alginate was purchased from Kikkoman Biochemifa Co. (Tokyo, Japan). Guar gum was purchased from San-Ei Gen F. F. I., Inc. (Osaka, Japan). All other materials were commercially available food grade products.

\section{Preparation of SPI}

SPI were prepared from commercially available defatted soybean flour by a standard process described earlier (Kanamori et al., 2012). 15 volumes of water was added to the flour, and the $\mathrm{pH}$ was adjusted to 7.0 by sodium hydroxide. After the precipitate was removed by centrifugation, the $\mathrm{pH}$ of the supernatant was adjusted to 4.5 . The precipitated protein was again collected by centrifugation, dissolved in water, and neutralized to $\mathrm{pH}$ 7.0. The content of dry-matter in the solution was approximately $10 \%$. The solution was heated at $120^{\circ} \mathrm{C}$ for $6 \mathrm{~s}$ and spray dried at air inlet and outlet temperatures of $180^{\circ} \mathrm{C}$ and $70^{\circ} \mathrm{C}$, respectively. Alginate and guar gum were added to the neutralized solution at a final concentration of $3 \%$ of the total dry-matter content in the solution, heated, and spray dried using the same conditions as mentioned above.

\section{Measurement of physical properties of SPI}

Gel strength of SPI was measured as described earlier (Samoto et al., 1997). Briefly, $167 \mathrm{~g}$ of SPI and $83.3 \mathrm{~g}$ of water were mixed in a food processor for $3 \mathrm{~min}, 2 \mathrm{~g}$ of sodium chloride $(\mathrm{NaCl})$ was added and mixed for $2 \mathrm{~min}$. The dough was deformed by a vacuum sealer, and poured into a casing tube $22 \mathrm{~mm}$ in diameter. The samples were heated in a water bath at $80^{\circ} \mathrm{C}$ 
for $30 \mathrm{~min}$, and allowed to stand overnight at $4{ }^{\circ} \mathrm{C}$. After readjusting the temperature to $20^{\circ} \mathrm{C}$, the gels were unpacked and cut to a height of $20 \mathrm{~mm}$. The breaking test was performed by Creep-meter RE-3305 (Yamaden Co. Ltd., Tokyo, Japan) at a rate of $5 \mathrm{~mm} / \mathrm{s}$ with an acrylic globular plunger $5 \mathrm{~mm}$ in diameter, and the breaking force was measured as gel strength.

Viscosity of SPI was measured at a concentration of $4 \%$ by a viscometer (MCR-302; Anton Paar Japan, Tokyo, Japan) with a coaxial cylinder system (CC27/T200/SS) at $10^{\circ} \mathrm{C}$. The solutions displayed a Newtonian shear behavior at shear rate ranging from 1 to $100 \mathrm{~s}^{-1}$, and the viscosities were determined by linear regression analysis of shear stress and shear rate.

Emulsifying ability of SPI was measured as the median diameter of emulsion prepared by ultrasound. $4 \mathrm{~g}$ of $4 \%$ SPI solution and $1 \mathrm{~g}$ of rapeseed oil were poured into a test tube $15 \mathrm{~mm}$ in diameter and $104 \mathrm{~mm}$ in length. Ultrasound treatment was performed for $1 \mathrm{~min}$ in an ice bath using an ultrasound machine (AUTO CHASER 300; Kaijo Co., Tokyo, Japan) with a transducer (No. 5281). Particle size distribution and median diameter of diluted emulsions were measured by a laser diffraction particle size analyzer (SALD-2000A, Shimadzu Co., Kyoto, Japan).

\section{Preparation of sausage}

The day before the production of sausage, the fat pre-emulsions were prepared in a cutting mixer (UMC-5; Stephan, Hameln, Germany). The $500 \mathrm{~g}$ of pre-emulsions consisting of SPI, water, and pork fat in a ratio of 1:6:6 were mixed at a speed of $3000 \mathrm{rpm}$ for $5 \mathrm{~min}$ at $4^{\circ} \mathrm{C}$. The sausage was prepared from a batter consisting of minced meat, pork fat, pre-emulsion, and crushed ice in a ratio of 35:20:33:12 was mixed in the cutting mixer at a speed of $1500 \mathrm{rpm}$ for $1 \mathrm{~min}$ at $4{ }^{\circ} \mathrm{C}$ and $3000 \mathrm{rpm}$ for 3 min under vacuum. $1.5 \% \mathrm{NaCl}, 0.4 \%$ Na-polyphosphate, $0.3 \%$ Na-glutamate, $0.25 \%$ white pepper, and $0.01 \% \mathrm{Na}$-nitrite were added to the batter and mixed at $3000 \mathrm{rpm}$ for $3 \mathrm{~min}$ under vacuum. The batter was poured into a casing tube $30 \mathrm{~mm}$ in diameter, and heated at $78^{\circ} \mathrm{C}$ in a water bath. After cooling in water, the samples were allowed to stand overnight at $4{ }^{\circ} \mathrm{C}$. The sausages were cut into $10 \mathrm{~mm}$ height and the hardness was measured as breaking force by an Instron testing machine (model 4302; Instron Japan Co., Ltd., Kawasaki, Japan) with Magnus-Taylor Puncture Probe (No. 2830-015H) at a speed of $100 \mathrm{~mm} / \mathrm{min}$ at room temperature.

\section{Preparation of salt-soluble meat protein (SSMP) and measurement of mixed gel properties}

SSMP was prepared according to a method described by DeFreitas et al. (1997) with a modification that the centrifugation was performed at $30000 \times \mathrm{g}$ for $30 \mathrm{~min}$. The dry-matter content of the resulting SSMP was $9.14 \%$ and the protein content was $6.39 \%$ (Kjeldahl method). Hardness of mixed gels of SSMP and SPI was measured according to method described by Tsumura et al. (2005) with a modification of using $5 \mathrm{~mm}$ cylindrical plunger. 


\section{Emulsifying property by a cutting mixer}

Na-alginate was used as a thickening agent, and tween 80 was used as a surfactant. Appropriate amounts of alginate were added to $200 \mathrm{~g}$ water and mixed by a cutting mixer (MK-K58; Panasonic Co., Osaka, Japan). $50 \mathrm{~g}$ oil (pre-mix of $49 \mathrm{~g}$ rapeseed oil and $1 \mathrm{~g}$ tween 80) was added to the mixer bowl and mixed for 5 min, simultaneously sampling at each time point $(0.5$, $1,2,3,4$, and $5 \mathrm{~min}$ ). Particle size distribution and median diameter of diluted emulsions were measured as described above.

\section{Statistical Analysis}

Statistical analyses were performed using IBM SPSS software (version 22).

\section{RESULTS AND DISCUSSION}

The physical properties of SPI and the sausages are shown in Table 1. The SPI with gums had higher viscosities and lower gel strength than the control SPI. The emulsifying properties were observed to be similar. The hardness of sausages fortified using SPI with gums was higher than that of sausages fortified using the control SPI. The particle diameter of the pre-emulsions of SPI with gums was smaller than that of the control.

The addition of gums to SPI had a preferable effect in terms of sausage hardness. Various factors influenced the physical properties of SPI. The gelation properties of both SPI and mixed gels with SSMP did not increase by the addition of gums; this showed that the increase in the hardness of sausage was not derived from gelation properties.

Table 1. Effect of addition of gum on SPI and sausage

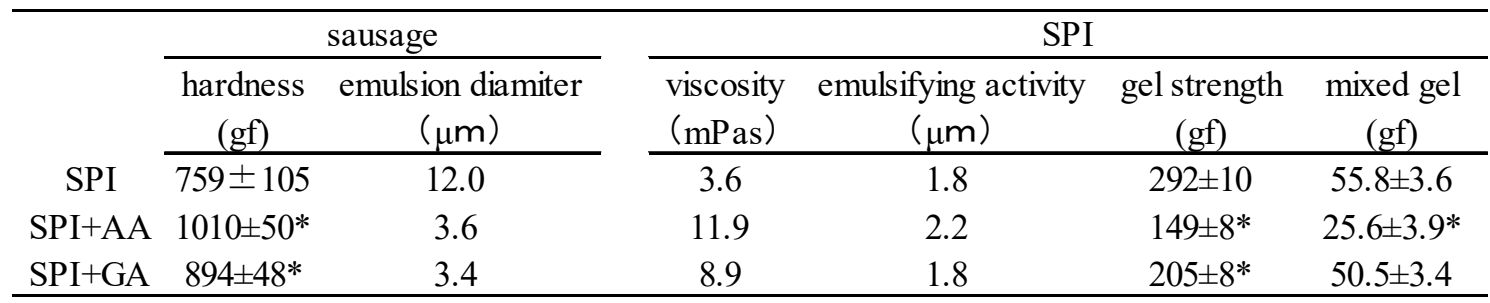

Median diameters of emulsions. ${ }^{*} \mathrm{P}<0.05$ was considered a significant difference as compared to SPI.

As the particle diameter of the pre-emulsions was considered to correlate with that of sausages, the sausage emulsions made from SPI with gums were finer than those made from the control SPI. It is known that oil droplets in gels behave as fillers and affect the rheological properties of the gels. A gel thickening filler is called "active filler" and gel thinning filler is 
called "inactive filler" (Gohtani et al., 2008). The effect of particle size of oil droplets was reported in SPI (Kim et al., 2001), soybean glycinin (Matsumura et al., 1993), agar (Kim et al., 1999), and egg (Kalkani et al., 2007). These reports revealed that the higher the droplet sizes, the lower the gel elasticity or strength. Based on this knowledge, in the present study, the droplet sizes were considered to affect the sausage hardness. However, the addition of gums did not change the emulsifying properties of SPI. Anything, but emulsifying properties of SPI, affected the droplet sizes of the sausages.

The viscosity of SPI was largely affected by the addition of gums. Several researchers reported the effect of viscosity on emulsifying property, but there was inconsistency between the results. Using a high-pressure homogenizer, Pandolfe (1981) demonstrated that the particle size was not affected by the viscosity in high viscosity range ( $>50 \mathrm{mPas})$, and that in the low viscosity range ( $<50 \mathrm{mPas}$ ), the particle size increased as the viscosity increased, which was contrary to this study. Qian and McClements (2011) reported that the particle size decreased as the viscosity increased which was in agreement with the results of the present study. We speculated that the discrepancy in results may be due to the emulsifying apparatus used-a cutting mixer has been rarely used for the study of emulsions-and the experiments were performed by using a simple model system.
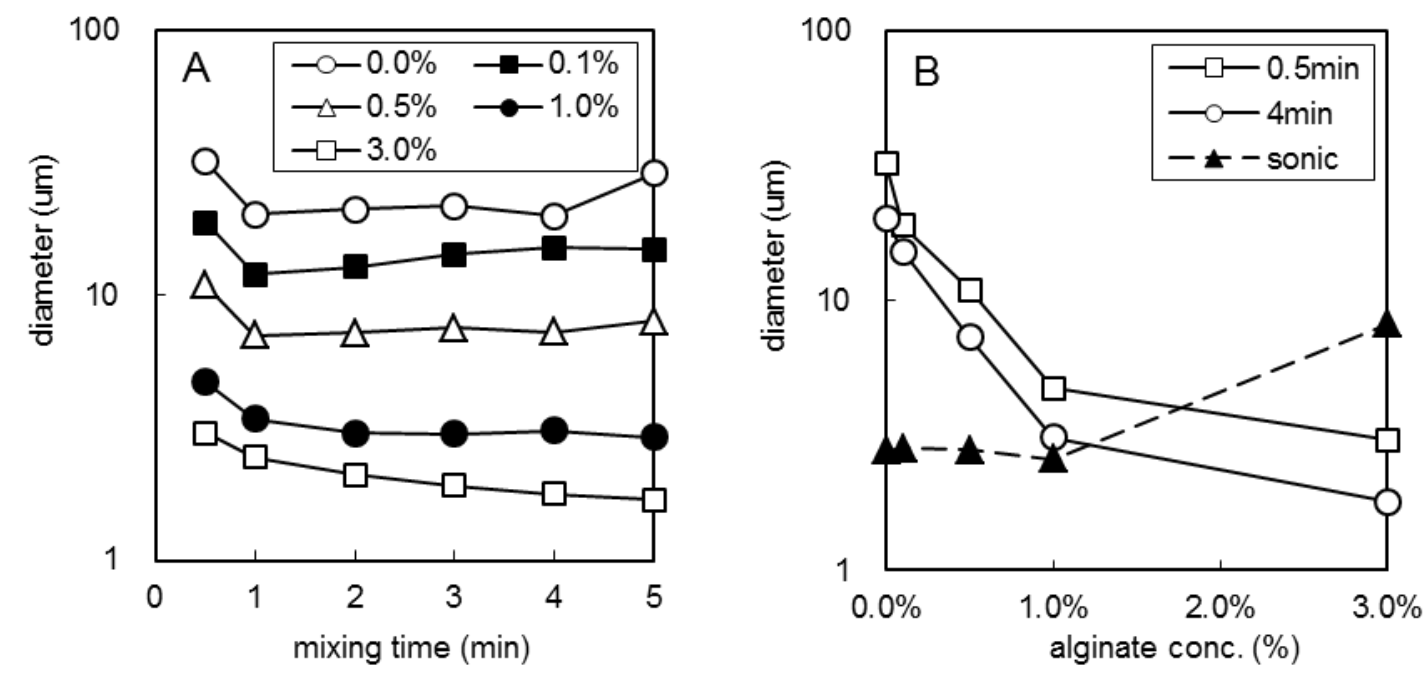

Fig. 1 Emulsion diameter during mixing. (A) Effect of mixing time. Symbols indicated data series of the alginate concentration. (B) Effect of alginate concentration. Symbols indicated data series of the mixing time.

The relationship between emulsifying property and concentration of thickening agent 
was investigated by comparing the preparation from a cutting mixer and that from an ultrasound apparatus (Fig. 1). Oil in water emulsion was formed in all cases and it was not broken by dilution of water. The particle sizes (median diameter) were slightly high at $0.5 \mathrm{~min}$ mixing at each concentration of alginate, and decreased to a steady value at 1 min mixing. The viscosity affected the emulsifying property significantly, because the particle sizes decreased as the concentration of alginate increased. No significant effect was observed by using an ultrasound below a concentration of $1 \%$ alginate; small particle size was observed even after no addition of alginate. The viscosity did not affect the emulsifying property by the ultrasound system. It was possible that the emulsifying property increased because of complex formation between the surfactant and the thickening agent. On the basis of the results obtained by using the ultrasound system, complex formation did not affect the emulsifying property. The median diameter of the particle increased at $3 \%$ alginate concentration. The reason was that the mobility of the solution was observed to be too less by sight and the emulsion was formed only in part. Taken together, the viscosity positively affected the emulsifying property by a cutting mixer. The emulsion sizes of the sausages improved due to the viscosities of SPI with gums, and consequently, the hardness of the sausages improved due to the emulsion sizes.

Most of the previous investigations were performed on the assumption that pulverization of dispersed phase was derived only from mechanical conditions. A cutting mixer has a wide gap between rotating edges and mixer bowl. When the continuous phase viscosity is low, the dispersed particles easily dodge the edges and the pulverizing energy is not transferred to them. Thus, the pulverization is not only derived from the mechanical conditions but also from the continuous phase viscosity.

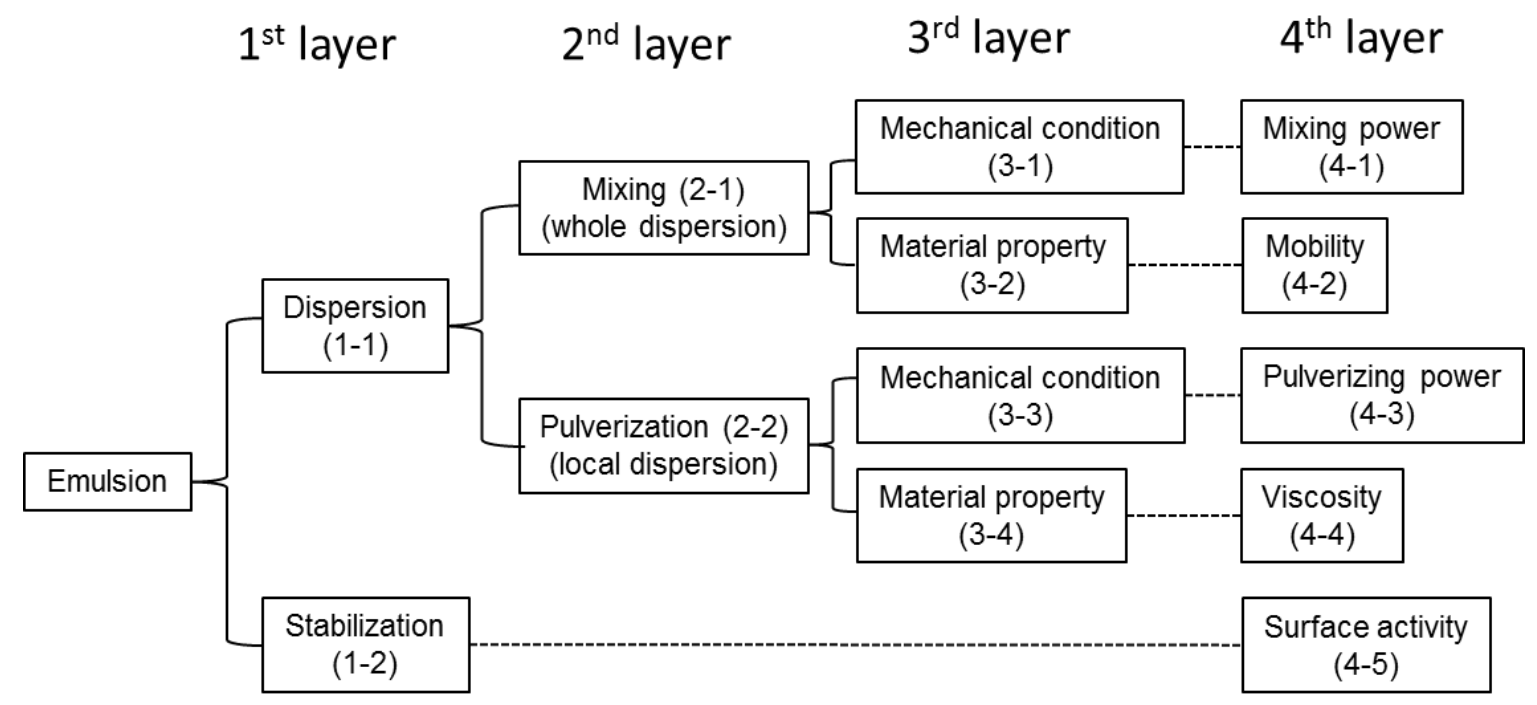




\section{Fig. 2 Logic tree of the factors affecting the emulsifying properties}

In the present study, the factors affecting the emulsifying property were sorted in a logic tree, which is often used in executive consulting (Minto, 2009) (Fig. 2). The emulsions represent dispersions in a second immiscible continuous phase (Darling and Birkett, 1987). In this study, the factors were grouped into meso-factors-the factors including other factors described previously (Kanamori, in submission) - in the manner of "mutually exclusive and collectively exhaustive (MECE)" in the first, second, and third layers, and the major factors of each meso-factor were extracted in the fourth layer. In the first layer, the emulsifying process was considered to consist of dispersion (1-1) and stabilization (1-2). The dispersion further consisted of whole dispersion and local dispersion, which were denoted as mixing (2-1) and pulverization (2-2), respectively. In the third layer, the properties that will affect each of these factors were divided into mechanical condition and material property. One of the major mechanical conditions (3-1) of the mixing was mixing power (4-1), and that of the material properties (3-2) was mobility of the continuous phase (4-2). One of the major mechanical conditions (3-3) of the pulverization was pulverizing power of the machine (4-3), and that of the material properties was viscosity of the continuous phase (4-4). One of the major factors of the stabilization (1-2)-it was not needed to be divided into second and third layers in this study - was the surface activity of the surfactant (4-5).

It was considered that the emulsifying property derived by high-pressure homogenization or ultra-sound usually used in food investigations was derived from the pulverizing power of the apparatus (4-3) and the surface activity of surfactant (4-5). In this study, a cutting mixer was used to emulsify, and the different factors affected to the emulsifying property. The dispersing ability of cutting mixers is not derived from the pulverizing ability of cutting mixers, which is not only derived from the mechanical power but also from the continuous phase viscosity as described above. The viscosity of the continuous phase affected both mixing (2-1) and pulverization (2-2). The former factor did not affect in the cutting mixer, because the edges were large enough to mix the whole system. In the ultrasound emulsion, it was a negative factor in terms of whole mixing and the experiments were performed at relatively low viscosities. In a fluid with a low viscosity, pulverizing ability of the ultrasound system was derived from the power of the apparatus (4-3), and the emulsifying property was determined only by the surface activity of surfactant (4-5) in a fixed mechanical condition. Even though the factors unrelated to this study were not listed in the logic tree, it is obvious that many other factors exist - hardness of dispersed phase, stabilizing effect of viscosity, and difference in 
specific gravities of dispersed and continuous phases. As all the factors will be much more complex including these factors, it is difficult to understand and control them without a logic tree.

\section{CONCLUSION}

Although most of the investigations of emulsion have been performed on the surface activity of surfactant, there was no effect on the sausages in the present study. The hardness of the sausages did not relate to the gelation property of added SPI. These phenomena were attributable to the viscosities of the SPI, which was revealed to be appropriate logically. Because the systematic sorting is essential to the understanding and the controlling of complex systems, the logic tree was considered as a useful tool.

\section{ETHICAL STATEMENTS}

Conflict of Interest: The author declares that he has no conflict of interest.

Ethical Review: This study did not involve any human or animal testing.

\section{REFERENCES}

Abdolghafour, B., \& Saghir, A., 2014. Development in sausage production and practices-A review. Journal of Meat Science and Technology, 2, 40-50.

Andrès, S., Zaritzky, N., \& Califano, A., 2006. The effect of whey protein concentrates and hydrocolloids on the texture and colour characteristics of chicken sausages. International Journal of Food Science \& Technology, 41, 954-961. doi:10.1111/j.1365-2621.2005.01152.x

Darling, D. F., \& Birkett, R. J., 1987. Food colloids in practice. Pages 1-29 in "Food emulsions and foams." ed. E. Dickinson, Royal Society of Chemistry, London.

DeFreitas, Z., Sebranek, J. G., Olson, D. G., and Carr, J. M., 1997. Carrageenan Effects on Salt

- Soluble Meat Proteins in Model Systems. Journal of Food Science, 62, 539-543. doi: 10.1111/j.1365-2621.1997.tb04425.x

Gohtani, S., Kaji-Fujita, T. and Yamano, Y., 2008. Effect of oil droplets on the compressive and sensory properties of monodispersed $\mathrm{O} / \mathrm{W}$ emulsion-gellan gum gel. Tech. Bull. Fac. Agr. Kagawa Univ., 60, 53-59 (in Japanese)

Hoogenkamp, Henk W., 2005. Soy protein and formulated meat products. CABI Publishing, 
Wallingford.

Joly, G., and Anderstein, B., 2009. Starches. Pages 25-55 in "Ingredients in meat products" ed. by Tarté, R. Springer, New York.

Kalkani, A., Paraskevopoulou, A., and Kiosseoglou, V., 2007. Protein interactions and filler effects in heat-set gels based on egg. Food Hydrocolloids, 21, 191-197. doi:10.1016/j.foodhyd.2006.03.011

Kanamori, J., in submission. Study of complex food systems I-filler effect as a meso-factor of bread making property.

Kanamori, J., Samoto, M., and Miyamoto, M., 2012. Noodles and noodle skins comprising soybean protein composition and the method of making same. U.S. Patent No. 8,124,157. 28.

Kim, K. H., Gohtani, S., Matsuno, R., and Yamano, Y., 1999. Effects of oil droplet and agar concentration on gel strength and microstructure of $\mathrm{O} / \mathrm{W}$ emulsion gel. Journal of Texture Studies, 30, 319-335. doi: 10.1111/j.1745-4603.1999.tb00220.x

Kim, K.H., Renkema, J.M.S. and T. van Vliet, 2001. Rheological properties of soybean protein isolate gels containing emulsion droplets. Food Hydrocolloids, 15, 295-302. doi:10.1016/S0268-005X(01)00028-5

Lin, K. W., and Mei, M. Y., 2000. Influences of Gums, Soy Protein Isolate, and Heating Temperatures on Reduced - Fat Meat Batters in a Model System. Journal of Food Science, 65, 48-52. doi: 10.1111/j.1365-2621.2000.tb15954.x

Liu, K., 2000. Expanding soybean food utilization. Food Technology, 54, 46-59.

Lusas, E. W. and Rhee, K. C. 1995. Soybean protein processing and utilization. Pages 117-160 in: Practical Handbook of Soybean Processing and Utilization. D. R. Erickson, ed. Published jointly by AOCS press: Champain, and United Soybean Board: St. Louis.

Matsumura, Y., Kang, I. J., Sakamoto, H., Motoki, M., and Mori, T., 1993. Filler effects of oil droplets on the viscoelastic properties of emulsion gels. Food Hydrocolloids, 7, 227-240. doi:10.1016/S0268-005X(09)80174-4 
Minto, B., 2009. The pyramid principle: logic in writing and thinking. Pearson Education, Harlow.

Pandolfe, W. D., 1981. Effect of dispersed and continuous phase viscosity on droplet size of emulsions generated by homogenization. Journal of Dispersion Science and Technology, 2(4), 459-474. doi:10.1080/01932698108943924

Qian, C., and McClements, D. J., 2011. Formation of nanoemulsions stabilized by model food-grade emulsifiers using high-pressure homogenization: factors affecting particle size. Food Hydrocolloids, 25, 1000-1008. doi:10.1016/j.foodhyd.2010.09.017

Samoto, M., Akasaka, T., and Mori, H., 1997. Process for preparing fractionated soybean proteins and foods using the same. U.S. Patent No. 5,597,607. 28.

Tsuge, K., Kanamori, J., Samoto, M. and Akasaka, T., 2004. Japan Patent P3570470.

Tsumura, K., Saito, T., Tsuge, K., Ashida, H., Kugimiya, W., and Inouye, K., 2005. Functional properties of soy protein hydrolysates obtained by selective proteolysis. LWT-Food Science and Technology, 38, 255-261. doi:10.1016/j.1wt.2004.06.007 